\title{
Formação docente em Educação Física: experiências sociais e relação com o saber
}

\author{
Zenólia C. Campos Figueiredo*
}

\begin{abstract}
Resumo: Este artigo busca analisar como as experiências sociais, mais especificamente as experiências sociocorporais dos alunos de um curso de formação inicial em Educação Física agem como um filtro no processo de formação destes alunos, orientando escolhas e definindo interesses, relações e a valorização de determinados conteúdos curriculares, em detrimento de outros, enfim influenciando a trajetória acadêmica destes estudantes. Palavras-chave: Experiências Sociais, Formação Inicial em Educação Física, Currículo.
\end{abstract}

A Educação Física ocupa, em nosso meio, a posição de principal promotora da saúde ${ }^{2}$ e, muitas vezes, no imaginário da população, é relacionada apenas ao aspecto biológico, sobretudo dentro das escolas e, mesmo fora delas, no trabalho desenvolvido em academias, clubes, "escolinhas de esportes", orientação ao exercício, dentre outros.

A estreita vinculação entre Educação Física e saúde e Educação Física e esporte tem sido, ao longo dos anos, a principal referência dos alunos que ingressam no curso de Educação Física e, ao mesmo tempo, um entrave para que se possa compreender a Educação Física em uma dimensão educacional mais ampla e também suas interfaces com diferentes campos de sabe-res. Hoje, pode-se dizer que essa é a preocupação primordial de

* Professora Assistente do Centro de Educação Física e Desportos da Universidade Federal do Espírito Santo.

1 Este artigo corresponde a uma parte da tese de doutorado de minha autoria intitulada: "Experiências Sociais no Processo de Formação Docente em Educação Física" (2004).

2 Sobre a noção de saúde e atividade física em uma perspectiva para além do enfoque das Ciências Biológicas e com base nas Ciências Humanas e Sociais, sugerimos os estudos da professora Yara Maria de Carvalho (1998; 2001).

Movimento, Porto Alegre, v. 10, n. 1, p. 89-111, janeiro/abril de 2004 
alguns professores de Educação Física em universidades que formam professores dessa disciplina. Neste sentido, torna-se pertinente indagar: Qual deve ser o perfil dessa formação? Formamos professores ou profissionais ${ }^{3}$ em Educação Física para atuarem em espaços não escolares?

Estas são questões relacionadas à formação profissional, sobretudo, se considerarmos que a maioria dos cursos de Educação Física no Brasil, ainda possuem formação única em licenciatura. Há, portanto, necessidade de reflexão sobre o papel da formação inicial e do currículo em um curso de graduação em Educação Física. No entanto, é importante destacar que muitos alunos que ingressam no curso de Educação Física já trazem uma concepção dessa área de estudos como promotora de saúde restrita ao aspecto biológico como sistema de treinamento de atletas, instrutora de exercícios físicos e outras do mesmo gênero.

A Educação Física, hoje, pode ser compreendida como área que tematiza/aborda as atividades corporais em suas dimensões culturais, sociais e biológicas. Assim, a Educação Física extrapola a questão da saúde, relacionando-se com as produções culturais que envolvem aspectos lúdicos e estéticos, deixando de ter como foco apenas o esporte ou os exercícios físicos voltados para uma perspectiva restrita à promoção e ao desempenho de atividade física.

Além disso, ingressar num curso de Educação Física vem, cada vez mais, significando para o aluno a busca de uma formação que o capacitará a trabalhar na área da saúde. Ainda hoje, o próprio ensino de Educação Física tem contribuído para desenvolver essa visão, abrigando alguns grupos que buscam identificá-la com a área de Ciências Biológicas, fundamentando, assim, seus estudos em conhecimentos dessa área e rejeitando estudos que utilizam a produção das Ciências Humanas para pesquisar questões que emergem, de forma crescente, no campo da Educação Física.

3 Sabemos que o professor é um profissional. Essa distinção apresentada tenta expressar apenas um entendimento comum entre alunos e alguns professores do curso de Educação Física de que para atuar no espaço não escolar não se faz necessário ter um conhecimento pedagógico e de que o sujeito que atua no espaço não escolar é um profissional e não um professor.

Movimento, Porto Alegre, v. 10, n. 1, p. 89-111, janeiro/abril de 2004 
Este aspecto se agrava quando observamos que alguns alunos, por desinformação, chegam a pretender se especializar em áreas como a Fisioterapia ao final do curso, enquanto outros resistem à idéia da licenciatura e buscam ou pretendem buscar outra formação, muitas vezes, para o mesmo curso em que não conseguiram aprovação no vestibular anterior ao de Educação Física. Parece que apenas uma parcela menor de estudantes são sensíveis e se interessam pela perspectiva em que a Educação Física é trabalhada em sentido mais amplo, incluindo aspectos biológicos, mas indo além deles na busca de uma compreensão sócio-histórica e cultural da área.

Maurice Tardif, no texto "Saberes Profissionais dos Professores e Conhecimentos Universitários: elementos para uma epistemologia da prática profissional dos professores e suas conseqüências em relação à formação para o magistério", argumenta que as experiências sociais/culturais do aluno agem/funcionam como um filtro através do qual ele seleciona/aceita/adere/ rejeita os conhecimentos dos cursos de formação. Esses filtros, cognitivos, sociais e afetivos, processadores de informações, perduram ao longo dos tempos já que têm sua origem na história escolar e na história de vida dos alunos. Para o autor, essas experiências sociais são responsáveis pelo fato de que alguns alunos em formação inicial passem pelos cursos sem mudar suas visões/concepções anteriores.

Na mesma direção e no âmbito mais específico da Educação Física, em realidade portuguesa, Carreiro da Costa (1996), com base em Larry Locke, chama a atenção para o fato de que a maioria dos cursos de formação em Educação Física produz um impacto muito limitado nos estudantes. Retomando outros estudos, afirma que o longo período de aprendizagem dos alunos vivido dentro ou fora do contexto escolar, une-se "[...] às convencionais práticas culturais da Educação Física e dos desportos, para os equipar com um certo conhecimento acerca do que é o trabalho de professor" (Carreiro da Costa, Carvalho, Diniz e Pestana, 1996, p. 58).

Com base nesta literatura, partimos do pressuposto de que a experiência social do aluno, construída durante sua trajetória, dentro e fora da escola, interfere, influencia e/ou, de alguma forma, modela o perfil de formação inicial. Queremos dizer que o aluno, com base nas experiências sociais (assumidas, nesse estudo, como as vivências proporcionadas pelas interações que

Movimento, Porto Alegre, v. 10, n. 1, p. 89-111, janeiro/abril de 2004 
ocorrem nas relações sociais que incluem atividades e experiências corporais e valores a ela atribuídos) realiza ações, interações, hierarquizações, escolhas e, sobretudo, filtra o conhecimento acadêmico que lhe interessa no locus da dinâmica curricular.

As experiências sociais mencionadas por Tardif, no caso da Educação Física, advêm de diferentes fontes, tais como: ginásticas, esportes, lutas, danças, jogos, etc. e que foram, sobretudo, vivenciadas antes da formação inicial, não deixando de ocorrer, também, durante o período em que realizam o curso de Educação Física. Podemos dizer que essa prática é tão presente e marcante no currículo que, por vezes, os alunos a sobrepõem aos saberes curriculares, disciplinares, etc. De certa forma, isso corrobora a afirmação de Tardif, no sentido de que muitos alunos passam pelo curso de Educação Física sem mudar suas concepções anteriores ao ingresso no curso.

Essa filtragem, que o aluno realiza com o conteúdo do curso, se apresenta de diferentes formas, como por exemplo, na forte rejeição ao conhecimento pedagógico da Educação Física demonstrada por muitos alunos.

Buscou-se, então, analisar de que maneira o aluno, informado por suas experiências sociais, interage com os saberes mobilizados na formação inicial em Educação Física; como essas experiências agem no processo de formação, na orientação de trajetórias, escolhas e valorizações, funcionando como filtro de diferentes aspectos curriculares.

Organizamos o artigo da seguinte maneira: uma primeira parte, sobre as definições de "experiência social" e "relação com o saber"; uma segunda parte, destinada a algumas análises" dos memoriais, entrevistas em grupo e entrevistas individuais realizadas com alunos de um curso de formação inicial em Educação Física, sobretudo, no que diz respeito as hierarquizações, escolhas e relações com o saber construídas no curso, além de inferir considerações e possíveis implicações dessas ações para a formação em estudo.

\footnotetext{
4 Para maior conhecimento dos pressupostos teórico-metodológicos, referencial de análise, caminhos percorridos no trabalho de campo, instrumentos utilizados na pesquisa e outros detalhes da investigação, sugerimos a leitura da tese referida em nota anterior
}

Movimento, Porto Alegre, v. 10, n. 1, p. 89-111, janeiro/abril de 2004 


\section{Noção de experiência social}

Falar de experiência, simplesmente, é bastante impreciso se considerarmos a forma como o termo é empregado corriqueiramente. Em nosso dia-a-dia, a experiência é considerada como conhecimentos/habilidades adquiridas na imersão em determinada atividade. De acordo com o dicionário Aurélio (1986) as acepções do termo experiência são de experimentar, prática de vida, habilidade resultante de um exercício contínuo, arte ou ofício, conjunto de conhecimentos individuais ou específicos. Neste sentido, é solicitada (jornais, entrevistas, etc) como pré-requisito para se conseguir um emprego, como passaporte para legitimar algum discurso, ou, ainda, significando algum tipo de poder como no usual chavão popular "Falou a voz da experiência!".

Entretanto, a noção de experiência que nos interessa, mais propriamente, está situada dentre as teorias contemporâneas das Ciências Sociais que recusam a concepção clássica da ação, pautada, sobretudo, na identificação total do ator com o sistema numa sociedade "natural". Na perspectiva sociológica que assumimos os atores "[...] constróem a sociedade nas trocas quotidianas, nas práticas lingüísticas, nos apelos à identidade contra um sistema identificado com a racionalidade instrumental, com a produção da sociedade como mercado [...]" (Dubet, 1994, p. 14).

Ao tomar como ponto de partida a experiência para além de sua compreensão semântica, se impõe a necessidade de explicar a compreensão epistemológica que utilizamos. O conceito de experiência a que nos referimos emerge do "estilhaçamento" da sociologia clássica ou a partir das especializações e, ao mesmo tempo, da diversidade de paradigmas em torno das noções de sociedade, de indivíduo e de suas ações.

As "sociologias" da ação rejeitam tanto o estruturalismo funcional, como o pós-estruturalismo que proclama a "morte do sujeito" ao mesmo tempo que se afastam das tradicionais teorias da ação social que enfatizam a inter-dependência entre o ator e o sistema, pois reconhecem que há uma capacidade de iniciativa e de escolha nos indivíduos.

É neste sentido que Dubet (1994), se apropriando de diferentes idéias da sociologia consubstanciadas em concepções diferenciadas sobre a ação, situa essas definições nas duas grandes vertentes do "estilhaçamento" do modelo clássico: o mode-

Movimento, Porto Alegre, v. 10, n. 1, p. 89-111, janeiro/abril de 2004 
lo da comunicação e o modelo da ação racional. A seguir será discutido de maneira sintética, como estes dois modelos são concebidos.

O modelo da comunicação envolve duas idéias sobre a ação. Na vertente da comunicação, apresentam-se duas definições complementares de ação: a ação é interação e a ação é linguagem. Por um lado, entender a ação no campo da interação significa dizer que "[...] não são os papéis, as normas e os valores que comandam a acção social, mas as relações cara a cara nas quais os actores põem em prática estratagemas e competências que fixam as suas identidades [...]" (Dubet, 1994, p. 82). É importante entender que as interações não são previamente organizadas e decididas; ao contrário, elas se desenvolvem num tempo e espaço próprios. Por outro lado, a ação definida como linguagem critica a idéia do entendimento de ação como papel ou função determinada e a define como expressões simbólicas e construções da realidade. "A ação é tão-só a realização da própria actividade, e a reflexividade do actor está na linguagem [...]" (Dubet, 1994, p. 85). A ação social é uma organização da ação, da intencionalidade e da descrição.

No modelo da ação racional, apresentam-se outras duas definições complementares de ação: a ação é estratégia e a ação é utilidade. Na noção de ação como estratégia, o ator se orienta "[...] pelos seus interesses, pela percepção que tem deles e pelas regras da organização. E uma estratégia que se situa num espaco de jogo que ele não escolhe mas que pode modificar ao jogar" (Dubet, 1994, p. 86). As estratégias dos atores são racionais, na medida em que agem de acordo com seus interesses pessoais, e são culturais, considerando as normas, organização, valores... que incidem sobre as ações. A ação definida como utilidade circunscreve-se na via de um individualismo racionalista, a partir de escolhas individuais impulsionadas por interesses racionais, sem deixar de lado o aspecto subjetivo do ator que realiza tais escolhas.

O sentido polissêmico de experiência, podendo ser compreendida como uma maneira de sentir, individual, representada pelo "vivido" ou como atividade cognitiva, maneira de construir o real, de verificar, de experimentar, enfim, para o sociólogo, remete à experiência para o social, como uma forma de construção da realidade. "Deste ponto de vista, a experiência social não é uma 'esponja', uma maneira de incorporar o mundo por meio das emoções e das sensações, mas uma maneira de construir o mundo." (Dubet, 1994, p. 95).

Movimento, Porto Alegre, v. 10, n. 1, p. 89-111, janeiro/abril de 2004 
A noção de experiência social construída por Dubet (1994) e apropriada em nosso estudo inclui dois aspectos: a prática social e as lógicas de ação.

Em relação à prática social pode-se dizer que é constituída por definições e princípios. As definições estão assentadas nos seguintes pontos: a) o ator não está totalmente socializado; b) a ação está relacionada à subjetividade; c) a experiência social é construída; d) a experiência social é crítica. Dos princípios, entende-se que, se o sujeito tem que gerir várias lógicas, conseqüentemente, a ação social não tem unidade. Da mesma maneira, se a construção da ação se processa na experiência social, são as relações sociais que a configuram. Além disso, a experiência social se define pela conjugação dos vários elementos que atuam nos encontros e interações sociais.

Em relação às lógicas de ação pode-se dizer que a ação que constitui cada experiência social é resultante de lógicas de ação, denominadas pela Sociologia da Experiência como integração, estratégia e subjetivação.

$\mathrm{Na}$ lógica de integração, predomina o pensamento de que a sociedade é um sistema de integração. Neste sentido, o sujeito é visto como uma espécie de sujeito-individualizado, representante dele próprio, de sua posição, de sua tradição herdada. Trata-se de uma identificação construída pelo ator coerente com a manutenção ou com a mudança social, em que sua identidade, no jogo das relações sociais, é demarcada por relações de distância, diferenças e hierarquias, a fim de manter a integração coletiva.

A lógica da estratégia implica uma racionalidade técnica, uma racionalidade instrumental. A ação lógica é concebida em um patamar utilitário de regulação, a fim de manter regras individuais ou coletivas. Nessa perspectiva "[...] as relações sociais são definidas em termos de concorrência, de rivalidade mais ou menos viva dos interesses individuais ou colectivos." (Dubet, 1994, p. 124).

Interessante notar que na noção de "habitus", em Bourdieu, as lógicas de estratégia e integração se confundem na medida em que o "habitus" é um "ser" - identidade integradora - e também um recurso estratégico. Para Dubet (1994), as duas lógicas podem estar ligadas, mas não se confundem.

Movimento, Porto Alegre, v. 10, n. 1, p. 89-111, janeiro/abril de 2004 
A subjetivação aparece, de forma indireta, na ação crítica do ator que adota uma postura diferente em relação ao sistema. Essa ação ou atividade crítica supõe uma lógica social e cultural coletiva na qual o ator se experimenta como sujeito. Nesse sentido, o sujeito constrói seus próprios objetivos, expectativas e experiências sociais.

Essas respectivas lógicas de ação, de certa maneira, traçam para os atores determinadas representações sociais no sentido de se vincular ou não ao sistema. As formas como o ator se liga ao sistema podem predeterminar suas experiências a partir da ótica de que a ação deixa de ser "autônoma". A autonomia, aqui, aparece, não como sinônimo de desligamento, separação, mas significando capacidade de agir como sujeito em conflito dentro das relações sociais, sendo, portanto, determinante e determinado por essas relações que the possibilitam construir e escolher suas próprias experiências sociais.

Tratamos de experiências sociais, mas nosso foco de interesse foram as experiências corporais dos alunos do curso. Não é possível desconsiderar que as experiências corporais são, também, sociais, por isso vimos utilizando da expressão "experiência sociocorporal".

Ao recebermos os "calouros", a cada início de semestre, entre os anos de 1988 e início de 2000, quando ocupava o cargo de coordenadora de um curso de Educação Física (CEFD/UFES), fazíamos a habitual pergunta: por que escolheram cursar Educação Física. Foram várias as respostas obtidas. Algumas podem ser situadas no campo da estratégia de ação, quando os alunos respondiam que a escolha se dera pela maior facilidade de ingresso em relação a outros cursos. Outras respostas estavam relacionadas às experiências no campo familiar, quando os estudantes respondiam que houve um incentivo de irmãos ou mesmo de pais que são professores de Educação Física. A maior parte das respostas afirmava que a escolha pelo curso decorria da identificação com o esporte de alto nível ou pela própria experiência escolar voltada ao esporte, ou seja pela experiência social que o aluno mantinha com essa área do saber.

Essa última, a nosso ver, é experiência social reveladora de uma identificação da Educação Física com o Esporte, imposta por uma cultura e relações sociais preexistentes. Pode-se considerar que a construção dessa identificação dos alunos não ocorre 
somente dentro da escola, mas talvez e, principalmente, fora dela. Nesse caso, a experiência escolar é regulada por fatores externos.

Após o ingresso, no decorrer do curso, notamos, que a relação dos alunos com os saberes curriculares é bastante regulada por suas experiências sociocorporais vividas anteriormente e produz ações específicas como valorizações e hierarquizações decorrentes de elementos inscritos subjetivamente em suas identidades. Em síntese, pode-se dizer que há uma conexão intrínseca entre as experiências dos alunos e suas relações com o saber.

\section{Experiência e "relação com o saber"}

$\mathrm{O}$ saber $_{\mathrm{v}}$ assim como a experiência, também tem um sentido polissêmico. Vem sendo compreendido como sinônimo de aprender ou como o domínio de informações ou de conhecimentos.

Desta forma, nos sentidos mais comuns do saber, encontra-se presente um sujeito que pode se colocar tanto na posição de aprender como na posição de obter informações ou adquirir conhecimentos. Nesse ponto de vista, "[...] qualquer tentativa para definir 'o saber' faz surgir um sujeito que mantém com o mundo uma relação mais ampla do que a relação de saber"(Charlot, 2000, p. 59).

Essa noção coloca o sujeito no centro das análises das relações com o saber, sobretudo porque é ele quem desenvolve, nessas relações, atividades de argumentação, verificação, experimentação, comunicação consigo, com o outro e com o mundo. Concluindo, é o sujeito quem constrói o saber numa relação dinâmica e cotidiana.

Diferentemente da noção de experiência que estuda a construção da subjetividade, a noção da relação com o saber busca explicar, com base na teoria que apresenta essa orientação, os fundamentos que subsidiam uma "sociologia do sujeito", cujo objeto é o sujeito como um conjunto de relações e processos.

Mesmo levando em conta essas diferenças referentes ao objeto, ambos estão envolvidos na compreensão da experiência social. Enquanto a sociologia da experiência trabalha com as 
subjetividades dos atores, nas quais a experiência está circunscrita, a "sociologia do sujeito" estuda o sujeito, suas relações e processos nos quais a experiência se faz presente.

Nessa última abordagem, interessou-nos compreender melhor a relação entre sujeitos e saberes. Optamos por utilizar elementos da concepção de relação com o saber elaboradas por Chariot e refletir sobre alguns elementos dessa abordagem na análise no desenvolvimento curricular do curso de Educação Física.

Uma das dúvidas que pode surgir nesse campo conceituai é se o saber é ou não diferente do aprender. Para Chariot (2000), aprender pode ser: adquirir um saber como conteúdo intelectual, dominar um objeto ou uma atividade ou adquirir formas de relacionar-se. Entendido assim, o "saber" representa um tipo particular de "aprender". O saber e o aprender implicam relações entre sujeito e saber e entre sujeito e aprender. Em Chariot (2001, p. 29), aprender e saber são definidos da seguinte forma:

Quando digo 'o aprender', refiro-me a todas as atividades, qualquer que seja sua natureza, que consistem em aprender, e aos seus resultados, qualquer que seja a natureza desse resultado. Adoto o substantivo 'saber' para os resultados de um tipo particular de 'aprender' que só existem pela linguagem e na linguagem...

Em síntese, "[...] não há saber sem uma relação do sujeito com esse saber" (Chariot, 2000, p. 63), bem como não há aprender sem uma relação do sujeito com esse aprender. O ponto central, então, passa a ser não discutir o que constitui o saber e o aprender em si, mas, sim, compreender as relações construídas pelo sujeito com o saber e com o aprender.

A relação com o saber é epistêmica e identitária, inseparavelmente, da dimensão social. Relação epistêmica, porque o sujeito, em uma dada situação de aprendizagem, coloca-se no lugar de apropriar-se de um saber-objeto, de dominar uma atividade que se inscreve no corpo. "O corpo é um lugar de apropriação do mundo, um 'conjunto de significações vivenciadas' [...]." (Chariot 2000, p.69).

A relação epistêmica com o aprender pode diferenciar-se de acordo com a natureza de cada atividade. Na medida em que dominar uma atividade confunde-se com o produto do aprendizado, estamos diante de um tipo de relação. No momento em que dominar uma atividade representa um saber-objeto, estamos diante de outro tipo de relação. Um exemplo citado por Chariot (2000), sobre essa diferença, diz respeito, respectivamente, à

Movimento, Porto Alegre, v. 10, n. 1, p. 89-111, janeiro/abril de 2004 
relação de aprendizagem ao aprender a nadar e ao aprender a natação. No primeiro exemplo, aprender a nadar confunde-se com a própria atividade ou com o produto do aprendizado; no segundo, aprender a natação, numa posição reflexiva, é atribuir à atividade uma aparência de um saber-objeto constituído por enunciados (normativos), como, por exemplo, os saberes que aquele tipo de atividade mobiliza.

Interessante refletir sobre essa relação epistêmica com o aprender em um contexto de formação de professores de Educação Física. Os dois tipos de relação parecem ser construídos pelos alunos; entretanto, a relação mais dominante, principalmente nas disciplinas optativas do curso estudado, eminentemente práticas, é a relação em que a atividade confunde-se com o produto do aprendizado. Percebemos, em nosso estudo, que, para a maior parte dos alunos, aprender determinados saberes curriculares/ como a Ginástica Olímpica, significa aprender a executar tal atividade.

Pode-se dizer que esse tipo de relação traz implicações para a formação de professores porque leva os alunos a uma dissociação entre a dimensão prática e a teórica e a uma certa tendência em desvalorizar os saberes normativos da Ginástica Olímpica como aspectos didático-pedagógicos, históricos e sociais, dentre outros, que vão além do domínio corporal de técnicas que resultem em uma execução. No caso da formação profissional em Educação Física, seria interessante que os alunos conseguissem realizar, associadamente, os dois tipos de aprender: o primeiro, apenas com objetivo de vivenciar a atividade; o segundo, com o objetivo de dominar o saber-objeto da atividade.

A mesma relação que ocorre na disciplina Ginástica Olímpica pode ser observada em outras disciplinas mencionadas pelos alunos no momento das entrevistas, como: Natação, Dança Moderna e Contemporânea e Voleibol. O aprender possui uma dimensão mais ampla que o saber, dotado de uma dimensão mais restrita, como, por exemplo, as especificidades teóricas circunscritas em cada uma dessas disciplinas.

Passemos a ver as relações construídas pelo sujeito com o saber. Da relação epistêmica específica com um saber-objeto, o saber pode assumir a forma de objeto somente através da linguagem, mais enfaticamente, da linguagem escrita na qual o

Movimento, Porto Alegre, v. 10, n. 1, p. 89-111, janeiro/abril de 2004 
sujeito consegue objetivar determinadas apropriações de saber, inclusive, sem mencionar a atividade que permitiu que aprendesse tal saber (Chariot, 2000).

Além dessa dimensão epistêmica, existe a dimensão identitária que toda relação com o saber apresenta. Como já dito, ambas, inseparáveis da dimensão social. Na relação identitária, "[...] aprender faz sentido por referência à história do sujeito, às suas expectativas, às suas referências, à sua concepção da vida, às suas relações com os outros, à imagem que tem de si e à que quer dar de si aos outros" (Chariot, 2000, p. 72)

Essa relação volta-se para a identidade do sujeito com o saber, consigo mesmo, com os outros e com o mundo. É, sobretudo, uma dimensão na qual a relação exterior (com o mundo e com os outros) é dependente da relação interna consigo próprio.

Por fim, considerar a dimensão social imbricada nas dimensões epistêmica e identitária é compreender que, tanto a relação do sujeito com o saber quanto a relação do sujeito consigo mesmo, com os outros e com o mundo, são relações sociais, em um mundo social. Em outras palavras, os sujeitos vivem num lugar social, influenciados ou não por outros sujeitos sociais, atendendo ou não a expectativas sociais, escolhendo e construindo ações sociais, valorizando ora mais, ora menos, suas experiências sociais.

\section{As experiências sociocorporais no decorrer da formação inicial: a hierarquização, as escolhas e a relação com os saberes das disciplinas}

Retornemos ao pressuposto de que as experiências sociais do aluno do curso de Educação Física funcionam como filtros que perpassam a dinâmica curricular para reconhecer a amplitude dessa ação, antes mesmo da inserção desse aluno no curso e durante sua formação inicial.

Se considerarmos, inicialmente, os critérios adotados para priorizar disciplinas no curso, bem como para escolher disciplinas acadêmicas curriculares, estaremos diante de influências que exercem sobre a dinâmica curricular em um curso de formação, as experiências sociocorporais construídas, pelos alunos, antes mesmo do ingresso no curso.

Movimento, Porto Alegre, v. 10, n. 1, p. 89-111, janeiro/abril de 2004 
No que se refere a critérios para priorizar disciplinas, evidenciamos influências de experiências anteriores no campo da Educação Física, bem como algumas estratégias relativas ao cumprimento do ofício de alunos.

Há, ao nosso ver, entre os alunos, uma tendência a valorizar as disciplinas da área biológica. Essa tendência está bastante ligada à concepção de Educação Física como promotora da saúde ${ }^{5}$ e essa concepção é construída tanto na formação específica, como nos ensinos fundamental e médio e, também, fora da disciplina - "Bom, eu acho que a gente acaba colocando sempre num primeiro plano àquelas que são relacionadas diretamente à Biologia e acabo sempre deixando um pouco mais para trás as disciplinas da área de humanas [...]" (Aluna do $1^{\circ}$ período/entrevista em grupo).

Um outro aluno prioriza ainda mais a área biológica e a contrapõe à área pedagógica da Educação Física - "Eu sempre gostei da parte bioniédica. O pessoal costuma dizer que tem a corrente fisiológica ou biológica e a corrente pedagógica da Educação Física e eu sempre me identifiquei mais com esse lado biológico, vamos dizer assim, sempre estudei mais por questão de gostar, até por dar mesmo mais importância à essa área. Eu amo, a vertente que eu quis escolher para minha profissão, ou seja, que eu quis optar pela Educação Física voltada para a área de academia, área de fitness, área de desporto, treinamento, então eu sempre me dediquei mais a essa área. Todas as disciplinas do biomédico, todas as disciplinas voltadas mais para essa parte de aptidão física, Fisiologia, coisas do gênero. A parte escolar eu faço por obrigação" (Aluno do $9^{\circ}$ período/entrevista em grupo).

Nesse caso, a valorização de disciplinas biológicas parece estar mais diretamente relacionada com as concepcões de Educação Física que representam e com suas experiências sociocorporais. Ambas as situações parecem ter favorecido uma determinada visão da área, destacando o último depoimento, do mesmo aluno que, em um outro depoimento, afirmou que ainda pretende cursar Medicina. Por outro lado, essa valorização está relacionada, também, com o ofício de aluno, já que, considerando tais

\footnotetext{
5 Saúde esta, vinculada a um conjunto de conceitos, comumente, vinculados a um sujeito abstrato. "O conceito de saúde, ao longo do tempo, significou: ausência de doença (visão simplista), completo bem-estar físico-psíquico-social (visão idealista), estar em um padrão 'normal' (normal/patológico, visão relativista), ou ainda diposição de superação das adversidades físicas, psíquicas e sociais (visão subjetivista)" (CARVALHO, 2001, p.13).
}

Movimento, Porto Alegre, v. 10, n. 1, p. 89-111, janeiro/abril de 2004 
disciplinas mais difíceis, as priorizam e, em decorrência disso, criam estratégias para obterem, prioritariamente, aprovação nessas matérias ou disciplinas.

A lógica da ação de priorizar algumas disciplinas em detrimento de outras é estratégica ao mesmo tempo em que parece fazer parte da experiência de ser aluno. Essa ação é contínua no decorrer do curso, mesmo quando as disciplinas biológicas deixam de ser predominantes - "[...] eu, particularmente, trabalho com o nível de cobrança mesmo, para ser mais sincero. Onde se cobra mais a gente prioriza mais para estudar, para ter que estudar para conseguir uma nota [...]" (Aluno do $5^{\circ}$ período/entrevista em grupo). Nesse caso, podemos pensar a noção de "habitus" porque a lógica de estratégia de ação mobilizada para atingir uma aprovação na disciplina é, também, integradora da experiência de ser aluno.

Houve duas outras justificativas diferentes para a ação de priorizar determinadas disciplinas. De acordo com um desses depoimentos, os conteúdos das disciplinas biológicas são diferentes entre elas e os conteúdos das Ciências Humanas parecem semelhantes entre uma disciplina e outra. A outra justificativa diferenciada das demais diz respeito à parte prática das disciplinas biológicas em contraposição às disciplinas das Ciências Humanas, consideradas muito teóricas.

De certa forma, o curso estudado favorece à construção dessa concepção de que as disciplinas "humanas" são teóricas porque vêm sendo dissociadas da prática, nas "biológicas", os alunos vêem essa relação. Talvez, esse seja o motivo de considerarem essas últimas mais significativas.

As ações mobilizadas pelos alunos para priorizar disciplinas no decorrer da formação indicam determinadas experiências construídas e associadas às experiências escolares nos ensinos fundamental e médio conforme notamos nas outras análises desenvolvidas na investigação. Por um lado, experiências sociais favorecidas pelas trajetórias dos próprios estudantes; por outro, proporcionadas pelas hierarquias em torno da disciplina Educação Física.

Alguns estudantes do curso de Educação Física não se vêem em processo de formação profissional. A representação que parecem fazer do curso está fortemente identificada com suas trajetórias individuais e com o prolongamento dessas trajetórias durante os quatro anos e meio de formação. A ação de priorizar

Movimento, Porto Alegre, v. 10, n. 1, p. 89-111, janeiro/abril de 2004 
as disciplinas biológicas e disciplinas mais práticas, representa uma transposição de algumas noções construídas anteriormente, transformadas em ações dentro do curso de Educação Física.

No que se refere a critérios para escolher disciplinas acadêmicas curriculares, como as chamadas optativas, as experiências sociocorporais anteriores são as principais referências, para as decisões dos alunos, assim como nas relações estabelecidas pelos alunos com os saberes dessas disciplinas.

O prolongamento de experiências anteriores no decorrer do curso, afirmado anteriormente, pode ser ainda claramente demonstrado no caso das escolhas por disciplinas optativas consideradas disciplinas práticas e realizadas, no curso estudado, a partir do $5^{\circ}$ período. Parcela significativa dos alunos afirma escolher disciplinas a partir de experiências passadas - "[...] na faculdade, quando finalmente pude optar por uma disciplina prática, revivi toda a 'minha trajetória no esporte. Fiz Ginástica Olímpica I e II, voleibol I e II, Futsal e Futebol de Campo I e II, entre outras" (Aluna do $9^{\circ}$ período/"memorial") ou a partir da afinidade e gosto por determinadas práticas corporais - "[...] porque eu acho que quem teve afinidade com o esporte vai acabar pegando, até porque não é só uma optativa, são várias, então no caso, eu fiz vôlei durante seis anos, continuo jogando quando eu posso e vou pegar como optativa porque é uma coisa que eu tenho afinidade, que eu gosto de fazer, eu tenho prazer em fazer, eu nunca fiz judô na minha vida mas eu não gosto [... ." (Aluna do $1^{\circ}$ período/entrevista em grupo).

Mas há também outros critérios secundários e menos recorrentes nos depoimentos dos alunos. Diferentemente da escolha a partir do fato de o aluno ter tido uma experiência específica com aquele determinado conteúdo, há casos em que a escolha ocorre, por motivo contrário: o aluno, considerando ter tido uma experiência ampla com certos conteúdos, escolhe disciplinas que mobilizam outros com os quais não havia tido nenhuma experiência anterior.

Associado ao critério de escolha por disciplinas com as quais o aluno não havia tido nenhuma experiência anterior, encontramos um objetivo e vontade comuns em aprender algo novo, em que melhoraria seu desempenho numa área em que quer investir e cujo conteúdo é trabalhado na disciplina "[...] eu só fiz aprofundamento em natação porque eu ainda tenho esperança que ele, que eu consiga a nadar
[grifos
nossos]
ou
dar
aula
de

Movimento, Porto Alegre, v. 10, n. 1, p. 89-111, janeiro/abril de 2004 
hidrogináslica ou alguma coisa do gênero..." (Aluna do $5^{\circ}$ período/ entrevista em grupo). "Um dos critérios assim, seria a disciplina que eu tenho menos conhecimento, natação que eu nunca fiz, eu gostaria de aprender a nadar [grifos nossos] e passar os conhecimentos de natação [...]" (Aluna do $1^{\circ}$ período/entrevista em grupo).

Para essas duas alunas, bem como para outros participantes da pesquisa, saber executar determinadas práticas corporais é imprescindível no processo de formação. A partir dessa idéia, devemos refletir sobre a relação que esses alunos vêm construindo com os saberes dessas disciplinas.

Tanto nas escolhas por disciplinas com as quais o aluno já teve vivência quanto nas escolhas por disciplinas cujo conteúdo ainda é pouco familiar, a experiência sociocorporal parece ter sido a grande referência. Na primeira condição, serve como prolongamento de práticas corporais vivenciadas; na segunda, como possibilidade de aprender novas práticas.

Tanto uma condição quanto a outra traz implicações para o curso de formação (licenciatura) em Educação Física. Os diversos alunos que partiram de suas experiências para a escolha de disciplinas cujos conteúdos julgavam conhecer, construíram um tipo de relação epistêmica com o aprender, pautada apenas no domínio de uma prática corporal, que significa a execução correta da atividade. Como esses alunos passaram anos de suas vidas praticando algum tipo de atividade corporal, confundem o domínio dessa atividade com o conteúdo da própria disciplina, ou seja, por já saberem executar as atividades referentes ao título da disciplina crêem saber todos os conteúdos da disciplina escolhida.

Essa ação de supervalorizar determinadas disciplinas, pautada quase que, exclusivamente, nas experiências sociocorporais, além de contribuir para a construção de apenas um tipo de relação epistêmica com o saber, também contribui para a construção, por parte de alguns alunos, do sentimento de que não aprenderam nada se comparado ao que já sabiam - "[...] eu vivenciei muito tempo, no colégio, um tipo de esporte, pratiquei, era treinamento mesmo, era o time do colégio. Então, aquilo que os professores passaram pra gente ficou muito bem enraizado, eu aprendi mesmo aquilo e, se eu tivesse que transmitir para os meus alunos, eu saberia muito bem aquilo que eu aprendi com os meus professores. Então, chegando aqui, o que eu aprendi não me acrescentou em nada. Minha experiência que eu tinha tido era o suficiente, nada mais foi acrescentado" (Aluna do $9^{\circ}$ perío-

Movimento, Porto Alegre, v. 10, n. 1, p. 89-111, janeiro/abril de 2004 
do/entrevista em grupo). Parece que o aluno filtra os conhecimentos voltados para o que já domina numa forma de cursar a disciplina sem grandes esforços.

Também no caso dos alunos que consideraram suas experiências sociocorporais anteriores como referência para não escolher disciplinas que trabalhassem conteúdos já conhecidos e vivenciados por eles, há construção da relação epistêmica. Agora, esses alunos buscam ter bom desempenho em uma área das práticas corporais por tratar-se de algo desconhecido ou que ainda não sabem fazer. Para eles, aprender os conteúdos da disciplina escolhida é ter um bom desempenho na modalidade de atividade ou prática corporal escolhida. A frustração ocorre, então, se o aluno não consegue aprender a executar os conteúdos mobilizados pela disciplina. "Natação, porque a grade não dava muitas possibilidades fora do desporto, porque, a princípio, eu não gostaria de fazer disciplinas de desporto, jogos de quadra, porque eu não tenho muita habilidade [...]. Natação, eu peguei porque eu não sei nadar, nunca aprendi, já entrei não sei quantas vezes em escolas e continuo não sabendo (risos) [...]" (Aluna do $5^{\circ}$ período/entrevista em grupo).

No registro dos discursos dos alunos no que se refere às escolhas por disciplinas, identificamos, além das diversas formas de hierarquização de disciplinas, uma forte valorização da prática e da experiência pessoal trazidas para dentro do curso.

Essa prática ${ }^{6}$ parece ser compreendida pelos alunos ora como aquisição de experiência, ora como instrumentalização e apreensão de certas habilidades. Na primeira compreensão, a prática é reduzida ao fazer, praticar, experimentar; na segunda, ao aprender determinadas habilidades técnicas corporais, vistas como necessárias para o ato de ensinar e/ou desempenhar a função de professor de Educação Física.

As disciplinas optativas, como vimos, em muitas casos, são escolhidas em função das habilidades do aluno com a atividade mobilizada pela disciplina. Para ele, saber fazer aquela determinada prática corporal é pré-requisito "/.../ optei por futebol e atletismo por afinidade. Também, eu jogo em clubes desde os onze anos, quan-

6 Sobre a prática em um contexto de formação profissional, ver: "O Estágio na Formação de Professores: unidade teoria e prática?". (PIMENTA, 2001)

Movimento, Porto Alegre, v. 10, n. 1, p. 89-111, janeiro/abril de 2004 
do comecei [...]" (Aluno do $5^{\circ}$ período/entrevista em grupo). "Eu escolhi futebol logo como primeira optativa no período passado [...] eu pratiquei futsal, fui atleta de futsal, não grande atleta, mas fui atleta [...]" (Aluno do $5^{\circ}$ período/entrevista em grupo).

De certo modo, alguns desses alunos parecem buscar a reprodução das experiências sociocorporais anteriores, chegando ao final do curso sem mudar suas concepções sobre a Educação Física. Desta forma, parece que irão sobrepor, na prática profissional, os saberes da experiência aos saberes da formação. Sobretudo, porque a grande referência e filtro na formação inicial foi sua própria experiência. Muitos chegam ao final do curso, sem perceber que mais importante que saber fazer é aprender a ensinar os conteúdos da disciplina Educação Física mobilizados na formação profissional.

Nessa ação, os conhecimentos pedagógicos são considerados secundários porque, para os alunos, não há diferença entre o saber fazer e saber ensinar.

Outros dois aspectos, para além da experiência sociocorporal como referência maior na escolha de disciplinas optativas, também foram considerados. Um, voltado para a aplicabilidade da disciplina no mercado de trabalho; outro, ligado mais à questão da organização da grade curricular e da competência do professor.

A utilidade do conhecimento é, também, pensada pelo aluno em termos de sua praticidade. Muitos dos alunos em formação atuam como professores de Educação Física em diversos espaços (formal e não-formal) de trabalho $\mathrm{e}$, por isso, esperam extrair das disciplinas os conteúdos e a forma que atendam aos seus interesses. "No $5^{\circ}$ período eu peguei Judô I e Recreação [...]. Recreação, porque eu comecei a fazer estágio com tênis e lá eu trabalhava com criancas e a gente sempre usava brincadeiras, jogos lúdicos e eu vi a possibilidade de estar fazendo recreação para aumentar os conhecimentos [...]" (Aluno do $9^{\circ}$ período/entrevista em grupo).

A maneira como as disciplinas estão organizadas no currículo também influencia na vida acadêmica dos alunos, na medida em que, segundo eles, acabam sendo obrigados a fazerem determinadas disciplinas para completar os créditos referentes ao Conhecimento Técnico e ao Aprofundamento de Conhecimentos.

Alguns alunos, principalmente do $9^{\circ}$ período, escolheram as disciplinas optativas em função do professor. Em nossa análise, identificamos que, ao longo da formação, há determinadas

Movimento, Porto Alegre, v. 10, n. 1, p. 89-111, janeiro/abril de 2004 
ações e/ou visões que sofrem mudanças e que dependem da etapa curricular no qual o aluno se encontra. Uma delas pode ser evidenciada, a partir dos critérios utilizados pelos alunos na escolha das disciplinas optativas.

Até meados do curso, o aluno utiliza suas experiências sociocorporais como critério principal e, a partir daí, passa a considerar, sobretudo, a competência do professor que ministra as disciplinas de seu interesse. Essa primeira mudança registrada por alguns alunos parece fazer parte de um procedimento comum, à medida em que vão construindo outras experiências na vida escolar de formação profissional.

$\mathrm{Na}$ opinião de um dos alunos participantes da pesquisa, a formação inicial parece não conseguir abalar a noção de Educação Física trazida para dentro do curso por alguns colegas "A pessoa entra aqui, por exemplo, direcionada para natação, faz as disciplinas, principalmente, Natação I e II e sai daqui especialista em natação. Jáo era antes de vir para cá, parte técnica. Aprendeu a parte didática ou não aprendeu, mas sai daqui achando que é especialista em natação, sendo que não diversifica. A pessoa chega aqui com uma visão, segue aquilo e não aproveita as diversas vertentes do curso [...]" (Aluno do $9^{\circ}$ período/entrevista em grupo).

$\mathrm{Na}$ raiz dessa transposição que os alunos fazem de suas experiências corporais para dentro do curso durante toda a formação ou da busca consciente pela reprodução dessas experiências, identificamos dois problemas. O primeiro, conforme já dito, é a influência direta no currículo, ocasionando mudanças "ocultas" no perfil do curso cuja opção é pela formação de professores e não de treinadores; o segundo é a influência na prática profissional desses alunos, concomitante ao curso e após a formação.

Este segundo problema revela a sobreposição do saber da experiência em relação ao saber acadêmico. Reconheçamos, então, que a experiência corporal no âmbito da Educação Física, quase sempre, determina a reprodução de experiências anteriores, além de representar um certo entrave para a construção de novos conhecimentos no processo ensino-aprendizagem, seja nos cursos, seja na prática profissional.

7 Os dados deixam implícito que o professor competente é aquele que têm conhecimentos pertinentes a disciplina; sabe transmitir os conhecimentos; articula o conhecimento da disciplina a realidade profissional.

Movimento, Porto Alegre, v. 10, n. 1, p. 89-111, janeiro/abril de 2004 
Para se ter uma idéia, ao questionar uma aluna do $5^{\circ}$ período, já atuando em escola com turmas de $5^{\text {a }}$ séries, sobre quais conteúdos havia selecionado, respondeu que selecionara a recreação e o esporte, principalmente, o voleibol e o futebol de salão. Perguntei, então: como e por que havia selecionado esses conteúdos, já que não tinha tido contato com esses conhecimentos específicos no curso. A aluna respondeu da seguinte forma: "/.../ busquei lá trás em minhas vivências mesmo e o que eu via e o que eu vi depois. Mas aqui mesmo" não, porque eu estava ingressando nas optativas" (Aluna do $5^{\circ}$ período/entrevista individual).

Esse intercruzamento entre a experiência sociocorporal do aluno de Educação Física e o currículo do curso levou-nos a considerar que, apesar de o currículo ter um objetivo mais amplo com relacão à formação na perspectiva da docência, seu desenho também não está proporcionando uma mudança quanto as representações dos alunos transportadas para o curso. Ainda está dividido em matérias básicas e matérias profissionais e dessa forma não dá, ao aluno, a oportunidade de uma melhor interação entre suas vivências sociais anteriores ao curso e aquelas existentes no curso. Por um lado, há forte valorização e/ou sobreposição de experiências passadas em relação aos saberes da formação; por outro, há um currículo ainda bastante pautado no modelo técnico linear.

As experiências são múltiplas conforme vimos até aqui e determinam, ora mais, ora menos, as hierarquizações, as escolhas, as relações com os saberes no processo de formação e na prática profissional. Questionemos, então, o que fazem os cursos de formação (licenciatura) em Educação Física para tentar mudar essa situação?

De maneira geral, podemos dizer que alguns cursos de Educação Física (licenciatura), não obstante as demais licenciaturas, apresentam falta de articulação entre teoria e prática e de dicotomia entre formação específica e formação pedagógica. Apresentam, também, a necessidade de construção de uma sólida formação e a ausência de uma conexão entre as disciplinas da formação e as disciplinas básicas, além de outros problemas. Podemos ainda dizer que a Educação Física vem tentando resolver alguns problemas históricos da área, como a ausência de uma identidade profissional e a falta de clareza acerca do seu objeto de estudo.

8 Referindo-se ao curso de Educação Física.

Movimento, Porto Alegre, v. 10, n. 1, p. 89-111, janeiro/abril de 2004 
No cerne da formação, a preocupação é com a tendência por uma formação generalista que vem atendendo, exclusivamente, a diversidade do mercado de trabalho com uma estrutura curricular que beneficia a fragmentação do conhecimento e a valorização das disciplinas de cunho biológico, com a ênfase na formação técnicoesportiva, que parece oferecer um certo caráter prático ao curso. Mais recentemente, nota-se, no campo, uma preocupação bastante acentuada com a prática pedagógica de professores que atuam em escolas na educação básica e no ensino superior.

Tais estudos, preocupados com a prática pedagógica na formação e em outros níveis de ensino, com o distanciamento entre a formação inicial e realidade educacional, com a constituição de saberes docente, com a utilização de referenciais da Educação em pesquisas da área, com a formação e ação profissional, destacando a importância da formação com um sólido referencial teórico, dentre outros aspectos, estão em construção e, ao nosso ver, representam esforços da área na tentativa de superar os problemas da formação em Educação Física.

Como essa parece ser uma longa caminhada, nossa formação revela-se bastante frágil, reprodutora desses problemas já enraizados na área e com dificuldades em superá-los. Fato é que as experiências trazidas pelos alunos para dentro do curso encontram reforços suficientes para consolidá-las, tanto por parte da estrutura curricular e dos conteúdos de algumas disciplinas, quanto por parte de alguns professores imersos em uma determinada visão da Educação Física.

Nesse sentido, concluímos como uma interpretação possível, que as especificidades da Educação Física, relacionadas com a representação dos alunos que ingressam no curso, estão muito identificadas com as experiências sociais e sociocorporais construídas nas trajetórias individuais, bem como as influências concretas dessas experiências, no decorrer do tempo de formação inicial, devem ser tomadas como referência no currículo de formação. Argumentamos, porém, que é preciso compreender e contemplar as experiências sociais do aluno do curso de Educação Física não apenas como forma de interação entre a cultura de origem e a cultura de formação, mas também como uma maneira de intervir e romper com algumas concepções incorporadas e transferidas para os cursos de formação.

Movimento, Porto Alegre, v. 10, n. 1, p. 89-111, janeiro/abril de 2004 
Formación docente em educación física: experiencias sociales y la relación con el saber Resumen: Este artículo intenta analizar cómo las experiencias sociales, en especial las experiencias sociocorporales de los almnos de

un curso de formación inical en Educación Física comportan como un filtro en el proceso de formación de estes almnos, orientando elecciones y definiendo intereses, relaciones y la valorización de determinados contenidos curriculares, perjudicando otros es decir, influjendo la trajectoria académica de estos estudiantes. Palabras-clave: Experiencias Sociales, Formación Inicial en Educación Física, Currículo.

Teacher formation in Physical Education: social experiences and relation with knowledge Abstract:

This paper looks into how the social experiences, more specifically social-corporal experiences, of the students of a Physical Education undergraduate course act as a filter in the educational process of these students guiding choices and defining interests, connections, valuing some course contents rather than others, thus influencing the academic path of these students.

Keywords: Social Experiences, Undergraduate in Physical Education, Curriculum.

\section{Referências}

CARVALHO, Yara Maria de. O mito da atividade física. 2. ed. São Paulo: Hucitec, 1998. Atividade física e saúde: onde está e quem é o "sujeito" da relação? Revista Brasileira de Ciências do Esporte, Campinas, v. 22, n. 2, p. 9-22, jan. 2001.

CARREIRO DA COSTA et al. Formação de professores em educação física: concepções, investigação, prática. Lisboa: Edições FMH, 1996.

CARREIRO DA COSTA, Francisco et ai. As expectativas de exercício profissional dos alunos de um curso que habilita para a docência: a formação (não) passa por aqui? In: CARREIRO DA COSTA, (Org.). Formação de professores em educação física: concepções, investigação, prática. Lisboa: Edições FMH, 1996.

Movimento, Porto Alegre, v. 10, n. 1, p. 89-111, janeiro/abril de 2004 
CHARLOT, Bernard. Da relação com o saber: elementos para uma teoria. Porto Alegre: ARTMED Editora, 2000.

CHARLOT Bernard (Org.). Os jovens e o saber: perspectivas mundiais. Porto Alegre: ARTMED Editora, 2001.

DUBET, Francois. Sociologia da experiência. Lisboa: Instituto Piaget, 1994.

DUBET, Francois; MARTUCCELLI. À l'école: sociologie de l'expérience scolaire. Paris: Editions du Seuil, 1996.

FERREIRA Aurélio Buarque de Holanda. Novo dicionário da língua portuguesa. 2 ed. Rio de Janeiro: Editora Nova Fronteira, 1986

FIGUEIREDO, Zenólia C. Campos. Experiências sociais no processo de formação docente em educação física. Tese (Doutorado em Educação) - Programa de PósGraduação em Educação, Universidade Federal de Minas Gerais, Belo Horizonte, 2004.

PIMENTA, Selma Garrido. O estágio na formação de professores: unidade teoria e prática? 4. ed. São Paulo: Cortez, 2001.

TARDIF, Maurice et ai. Os professores face ao saber: esboço de uma problemática do saber "docente. Revista Teoria \& Educação, v. 4, 1991.

TARDIF, Maurice. Saberes profissionais dos professores e conhecimentos universitários: elementos para uma epistemologia da prática profissional dos professores e suas conseqüências em relação à formação para o magistério. Revista Brasileira de Educação, n. 13, 2000.

TARDIF, Maurice. Saberes docentes e formação profissional. Petrópolis, RJ: Vozes, 2002.

Recebido em: 03/02/2004

Aprovado em: 12/02/2004

Zenólia C. Campos Figueiredo Av. Anísio Fernandes Coelho, 301 apto. $101 \mathrm{~A}$ Bairro Jardim da Penha 29060-670-Vitória ES zenólia@npd.ufes.br

Movimento, Porto Alegre, v. 10, n. 1, p. 89-111, janeiro/abril de 2004 